\title{
WORLDVIEWS AND DISCURSIVE CONSTRUCTION OF GMO RELATED RISK PERCEPTIONS IN TURKEY
}

\section{Giuseppe A Veltri and Ahmet Suerdem \\ Introduction}

On 26 October 2009, the Turkish parliament passed a regulation addressing the control of food products containing genetically modified organisms (GMO). The regulation sparked a heated debate on the effects of science and scientific knowledge on everyday life, which had been up to that point a largely undisputed subject in the Turkish public sphere. This paper takes advantage of the opportunity created by this controversy to analyse the public understanding of GMO-related risks from a new perspective. The case of Turkey is particularly interesting because it offers the possibility to analyse the introduction of a new technological concept into a socio-cultural context other than that of Western countries. Moreover, the possibility of observing the risk discourse from the perspective of a wider range of political actors that are not highly visible in other countries, such as Islamist and neoIslamist movements, makes the Turkish case even more notable. In this context, the aim of the present paper is to study how different worldviews that structure the Turkish public sphere discursively construct public perceptions of the potential risks and benefits of GMO.

Biotechnology has been at the centre of political debate, policy controversy, academic research and the public understanding of science studies for more than 20 years (Gaskell, Bauer and Durant, 1998). Initially, research on public perception of biotechnology was influenced by the "deficit model," which focused on scientific literacy and the correctness of the information available to the public (Bauer, Allum et al., 2007). The major concern of the "deficit model" has been the cognitive deficiency among the general population regarding technological issues (Miller, 1983). However, since the 1990s, the cognitivist bias of this approach has received heavy criticism, opening the space for "constructivist" approaches. According to these critiques, the gap between scientific and public understandings of technological issues occurs as a result of the way in which scientific knowledge is mediated through other domains of knowledge and belief in society. For example, studies influenced by the cultural theory of risk (Douglas, 1978; Wildaski and Douglas, 1982) emphasised that the perception of risk by different actors was motivated by their worldviews. Similarly, studies in the public understanding of science based on Moscovici's (2000) Social Representations Theory (SRT) have considered the possibility of contesting ways of conceiving a technological issue each being different from scientific knowledge itself. These studies have shown that common sense perceptions of technological issues by different social groups assimilated expert knowledge via creating hybrid forms of social representations (Moscovici and Duveen, 2008; Wagner, 2007; Bauer and Gaskell, 2002). Far from being a neutral and uniform entity, such technological movements are networks of 
contesting actors that take part within the public sphere, where each act in support of and thus shape different attitudinal judgments and public perceptions (Bauer, 2002). During this process, mass media plays a particularly important role in the enculturation and formation of social representations of technology since they form an arena for the negotiation of different worldviews (Bauer, 2005a).

In this paper, we adopt a similar perspective in order to understand how newspaper columnists representing different worldviews construct their own versions of GMO-related risks within the Turkish public sphere. Three theoretical frameworks inspired this study: Social Representation Theory (SRT), the cultural theory of risk, and actor-network theory (ANT). SRT contributed the idea of studying the way in which social representations of GMO are discursively constructed by different social actors; cultural theory provided a background understanding of how different worldviews are involved in this construction process; and ANT offered a way to map the network of relations that are both material (between actors) and semiotic (between themes).

We operationalized this conceptual framework through a mixed research design bridging qualitative and quantitative methods. Systematic interpretation is the Achilles' heel of discourse analysis. We think that the methodological procedures applied in this research offer a systematic and transparent base for interpretive analysis. Such a design provides us with a methodological map to ground our interpretations in demonstrating how different actors use language to construct GMO's risks from their perspectives. However, the methodological framework offered in this paper is not meant to replace interpretive analysis. Richness and sensitivity of language cannot be handled with formal tools alone. Therefore, at the final stage an interpretive semiotic-paradigmatic analysis complements the systematic analysis.

The paper is organised as follows: the next section discusses the aforementioned theories within the scope of risk perception. We then further elaborate on the rationale underlying our methodology. The paper continues with an application of the proposed methodology to the analysis of the discursive construction of social representations of GMO-related risks in the Turkish press and concludes with a discussion of our findings.

\section{Theoretical frameworks}

\section{Cognitive approaches to risk perception}

The study of risk perception concerning the introduction of a new technology has been at the centre of many debates since the 1950 s when mainstream research focused on individual cognitive processes. Within this tradition, risk has usually been defined as an objectively occurring event independent of the observing subject; that is, as a sort of probability estimate for the happening of a negative event (Brun, 1994). Another branch of research within the cognitivist tradition considers how individuals 
subjectively develop different risk perceptions. Adopting a psychometric perspective, this approach considers the notion of risk as a function of both objective attributes of the object of risk and subjective differences in cognition. Accordingly, it questions the pure objectivity of risk perception since individuals have bounded cognitive capabilities and therefore selectively use certain heuristics and hallmarks in order to reduce the cost of information (Fischoff, et al. 2000; Slovic, Finucane, Peters and MacGregor, 2004; Slovic, 2000; Peters, Covello \& McCallum, 1997; Biel and Dahlstrand, 1995).

The traditional psychometric approach has been reformulated by theories such as SARF (Social Amplification of Risk Framework; Slovic 1993; 2000), which emphasises the importance of social and cultural context. According to SARF, the representation of risk by media, social groups, institutions and individuals plays a substantial role in determining the overall magnitude and scope of risk perception. However, while SARF takes into account the role of context in risk perception, it still remains within the psychometric framework. This framework takes culture as unitary and internally coherent across groups and situations within the same context and depicts it as the manifestation of values presumed to be internalized in an unproblematic manner in the course of socialization. Accordingly, culture is seen as a simple reflection of a variety of coherently organized sets of attitudes, which embody an underlying latent variable (DiMaggio, 1997) reflecting the aggregate value traits of its members. In terms of risk perception, this reductionist view of culture is largely responsible for what Habermas (1989 [1962]) calls "social-psychological liquidation of public opinion", since it neglects the fragmented nature of the public sphere.

\section{Cultural Theory of Risk}

The 'Cultural Theory of Risk' represents a significant alternative to the psychometric approach. Douglas (1978) argues that risk perception is not governed by personality traits, individual or social values, needs, preferences or the attributes of the risk objects, but is a socially constructed phenomenon. What is perceived as dangerous, and how much risk is acceptable, is a function of one's adherence to a way of life and social learning. (Douglas, 1978; Wildavsky \& Douglas, 1982; Thompson, Ellis \& Wildasvsky 1990) Douglas clearly distinguishes between cultural bias, defined as 'shared values and beliefs', and way of life, which reflects the 'patterns of interpersonal relations'. Hence, according to a cultural theory of risk perspective, the study of values, heuristics and cognitive biases can only have partial explanatory power: "Cultural theory attempts to unify heuristics by suggesting that these chains have but one link: the internalization of social relations" (Wildavsky 1987, p.10). Cultural theory makes two basic claims about the relationship between ways of life and risk perceptions: First, certain modes of risk perception tend to associate better with certain ways of life. Second, individuals settle on risk perceptions that advance the way of life they adhere to. That is, 
they are subconsciously disposed to notice and credit risk claims that cohere with their way of life and to ignore and dismiss risk claims that threaten it. Since maintaining and advancing ways of life predispose their adherents to perceive risks selectively, conflicts in risk perception are essentially disputes over ideal forms of social life.

\section{Social Representation Theory (SRT)}

Cultural theory contributes to the understanding of risk perception by integrating individual-cognitive mechanisms with social-cultural selection processes. In this vein, the theory resonates with one of the most influential theoretical approaches in European social psychology: Social Representation Theory (SRT). SRT has its origins in Emile Durkheim's distinction between collective and individual mental representations. Moscovici reframed the term "collective representation" as "social representation" suggesting that the transition from pre-modern to modern societies has resulted in a move from stable and fixed common sense knowledge to a more fluid and plural one. Hence, compared to collective representations, social representations emerge in a more fragmented public sphere constituted by different perspectives reflecting different social positions (Farr, 1998).

The SRT approach focuses on the link between individual and social levels of analysis. Social representations are "systems of values, ideas and practices with a two-fold function: first, to establish an order which will enable individuals to orientate themselves in their material and social world and to master it; secondly, to enable communication to take place amongst members of a community by providing them with a code for social exchange and a code for naming and classifying unambiguously the various aspects of their world and their individual and group history" (Moscovici, 1973, p.13). In contrast to 'normative' approaches to social cognition (e.g. Nisbett \& Ross, 1980), differences in social representations should not be considered the result of false, weak, biased or deficient forms of knowledge (Bauer \& Gaskell, 1999). Social representations are what members of a community believe to be real in their actions - their "paramount reality" (Bauer \& Gaskell, 2008). Accordingly, identities, attitudes, and attributions become expressions of specific common sense perspectives motivated by the shared experiences of the members of a social group.

This perspective has important implications for understanding risk perception. Moscovici (2000) identified two forms of common sense: the first is immediate knowledge that results in the formation of scientific knowledge, while the second is indirect knowledge and results from the infusion of everyday life practical knowledge with scientific information. It is within the second sphere that new forms of representations emerge. Moscovici defines such 'second-hand' knowledge as 'social representations'. Contrary to the theories of attribution and social cognition, according to him a cognitive process is an actively constructed group project rather than a passive reflection of the external world to the mind. Here the emphasis shifts from interpersonal to inter-group interactions and 
to the subjective forms of reality viewed through the lens of group practices, interactions and communication.

Social representations theorists regard cognition as socio-cultural and dynamic, and hence as something that cannot be simply reduced to the level of the individual mental processes (Marková, 2003).

Social representations serve both symbolic and pragmatic functions (Cranach, 1992). Their symbolic function can be found in their capacity to turn something unknown and unfamiliar into something tangible and familiar, giving a sense of stability within the life-world conceptions of a community (Moscovici, 2000). They do not merely represent an external object but also locate the members of a community in their life worlds, providing them with an identity (Duveen, 2001). Hence, social representations have a political aspect protecting the group in periods of change as a form of resistance while at the same time signalling the need for changes to the agents of innovation (Bauer, 1994). Parallel to the worldview approach of the cultural theory, SRT maintains that risk perception is motivated by the social positions of the individuals and is actively constructed through the struggles over shaping the public sphere (Joffe, 2003).

SRT particularly finds application in public understanding of science studies since the theory was born from a study of how psychoanalysis has been appropriated by different worldviews within French society (Moscovici and Duveen, 2008). SRT goes beyond the known paths of 'vulgarization' and 'diffusion' (Bauer and Gaskell, 2008) of 'dignified knowledge' as the only means of explaining the popularization of science. Scientific theories and concepts become part of everyday life, the result being that they adapt across different social milieus. The result of this adaptation is no longer the acquisition of the complete original framework but a fragmented representational construct satisfying the common sense perspective of the relevant social milieu. Moreover, social representations serve active political, besides passive cognitive, purposes. In their more recent reflections on the status of Social Representations Theory, Bauer and Gaskell (2008) emphasise the synthetic power of the SRT and its ability to address the individualistic, cognitivist and anachronic shortcomings of the traditional attitude and risk perception research. In an earlier version of their paper, Bauer and Gaskell (1999) proposed through the "toblerone model" that attitudes and risk perception can be viewed as a function of group specific assessments bounded by a common project and motivated to order the world in terms of group perception of risks. This view is extended into a more dynamic "wind-rose" model, a metaphor borrowed from Latour (1987). The new model takes into account political interaction between social groups, thereby suggesting that representations are constituted in a dynamic relational process with the functional aim of resistance or dominance. 
The dynamic political approach of Bauer and Gaskell's (2008) “wind-rose” model grafts SRT onto actor network theory (ANT) as introduced by Latour (1987). Latour contends that science and technology studies have to focus on the dynamics of interactions between the actors. In this respect, ANT systematically avoids the 'technology vs. society' dualism and focuses on the processes through which technical entities transform into social constructs. According to ANT, entities acquire their form and attributes as a result of their relationship with other entities (Law, 1999). Society, organizations, agents and technological artefacts are all social forms generated by patterned networks (Loon, 2002). ANT does not distinguish between human and non-human actors and hence conceive them within their relational meaning and role (Law, 1992).

Latour (1992) extended ANT to material-semiotic relations, whereby constituting elements define and shape one another. As for textual contexts, entities such as laboratories, measuring devices, viruses, journals, medical authorities, political institutions, transport technologies, human organs and customs, only come to signify by virtue of their relations to other processes within a sign system. ANT depicts science as a process where bits and pieces from the social, technical and textual are configured together, and converted (or "translated") into a set of equally heterogeneous scientific constructs. However, this translation process does not occur as a stable co-ordinated system reflecting a single coherent reality (Callon, 1986). In a similar manner to SRT, ANT emphasises that the conception of events reflects irreducible multiple logics of classification and reality constructions because cognition occurs within different patterns of networks of relations. Materially and discursively heterogeneous logics constitute and reconfigure all kinds of actors within a network of a sign system that can only be analysed if we understand how these relations signify for these actors. In this sense, signification refers to a symbolic order and entails both a semiotic and a political ordering of meanings that can be analysed with semiotic tools.

ANT demonstrated its fertility through important studies (e.g. the work of Callon, 2007) that mapped networks that are simultaneously material (between entities) and 'semiotic' (between signs). This is also in line with the definition of social representations as "symbolically and materially loaded" relations (Rouquette \& Rateau, 1998). In this sense, operationalising how different actors construct different meaning configurations requires a semiotic approach representing actors and themes within the same network. Hence, next we will discuss the rationale and details of a methodology that allows for such an operationalisation.

\section{The rationale behind the methodology}

Given the theoretical framework discussed so far, this paper adopts a semiotic strategy, bridging 
quantitative and qualitative methods in order to understand how actors representing different worldviews politically deploy different GMO-related themes to organize their discourses. Although semiotic analysis has traditionally been an interpretive effort, formal-quantitative methodologies can be complementary because of their capacity in detecting and analysing meaning patterns (Suerdem 2009; Suerdem 2010).. Systematic allocation of meaning units such as words, paragraphs or symbols to thematic categories motivates the idea behind the formal semiotic analysis as developed here. Hence, detecting patterns within these categories and between the actors that utter them reveals the evaluative perspectives underlying the text. This idea makes quantitative techniques used for detecting structures and patterned regularities in a text compatible with interpretive semiotic analysis.

The first step for such formalisation is to determine basic meaning units and assign them to thematic categories. This can either be done in a deductive manner starting with a pre-established categorisation system informed by a theory or in an inductive manner first starting with "in-vivo" coding and organising them into categories. The second approach is more in line with the semiotic theory since it is concerned with the elicitation of an emic categorisation system from the structure underlying the entire text corpus itself. In that respect, we can refer to the work of cognitive anthropologists that have technically developed an inductive approach to detect native mental categories rather than imposing universal theoretical constructs on the data (Colby, 1996).

Methodologically, this perspective emphasises the procedures for detecting specific semantic systems and native categories embodying the patterns of everyday activities of a community. It starts by determining basic meaning units and then categorising them according to their co-occurrence patterns. The basic principle is to relate the semantics (meanings) to the pragmatics (social functions) of language, rather than studying the syntactic linguistic forms.

Cognitive anthropology uses computer-based automatic pattern detection techniques such as multidimensional scaling and cluster analysis widely. However, since semiotic analysis basically involves an interpretive effort, sole automatic categorisation of meaning units contradicts its logic. As meaning units are context-dependent, detecting their connotations requires human interpretation. On the other hand, interpretive methods are difficult to systematise. A great many problems for maintaining standards come from the ambivalent nature of qualitative data. In that sense, the use of thematic analysis (TA) offers a systematic approach to textual data-reduction by bridging the interpretive principles of qualitative research and the use of automatic pattern detection techniques (Guest and McLelland, 2003). The basic principle underlying TA is the detection, creation and application of codes to the meaning units in an interpretive manner. Moreover, like the pattern detection techniques mentioned thus far, TA is based on the discovery of identifiable themes and patterns within a corpus of textual data (Fereday and Muir-Cochrane, 2006). 
For TA, the development of a coding frame and the decision to label the meaning units under a code usually come from theory, literature, research experience or the data itself. Nevertheless, a theorydriven deductive coding frame carries the potential of imposing extrinsic categories and constructs onto the analysis, which clearly contradicts the 'pragmatic' aspects of semiotic analysis. CAQDAS such as NVIVO may help us to develop data-driven categorisation systems by searching for regularities and patterns among meaning units through interpretive human coding. Such software has query tools to elicit a matrix representation of the codes used in the corpus. The regularities in the distribution of particular codes with others are considered as the basis for patterns. However, these matrices provide us merely with the understanding of local recurring patterns of codes and, hence, miss the structure underlying the whole text. The task of organizing the produced codes into categories and assessing the level of abstraction in identifying themes are essentially left to the intuition of the researcher.

In order to employ a more systematic process, this study presents a hybrid approach. The first level of coding is obtained through an automatic analysis strategy that considers the overall corpus from the start and relates identified codes and themes backwards to the text. Hence, themes are determined according to the code co-occurrence patterns rather than being arbitrarily assigned or imposing a preestablished conceptual framework. Combining automatic categorization methods for developing an inductive categorisation system and using this as a coding frame for interpretive human coding may provide us with a systematic method without losing the interpretive perspective in coding. This methodology, we believe, is better suited to capturing relational aspects rather than using a completely 'human' qualitative analysis, which would be more suitable to a fine-grained analysis and a "thick description" of the meanings of themes and sub-themes.

\section{Methodology}

The methodology applied in this research combines qualitative and quantitative techniques at different stages of data analysis (for a summary diagram of methodological steps involved, see figure 2) Before proceeding to the analysis, raw textual data were prepared by applying pre-processing mechanisms, like data import, stemming, exclusion of non-content bearing concepts and synonym detection. Since the software used (WordStat, Peledeau, 2005) does not have built in pre-processing mechanisms for the Turkish language, this procedure involved a manual process. Turkish words and phrases in the text which have the same stem, together with synonyms of them, were sorted into 65 higher-level English keywords. Next, we employed a data-driven automatic categorization strategy as the first analytical stage. For this purpose, we computed a proximity matrix based on the co-occurrence of keywords within sentences. This proximity matrix was then used as an input to cluster analysis. 
At the next stage, the cluster analysis of the proximity matrix provided a dendogram revealing twenty thematic categories organised as clusters (right side of Figure 1) of keywords (left side of Figure 1). The clusters obtained are labelled according to a common theme underlying the keywords they contained. For example, keywords such as 'biodiversity', 'imperialism', 'resources', 'control of food stocks' appearing in the same cluster are labelled as the "dependency" theme. 


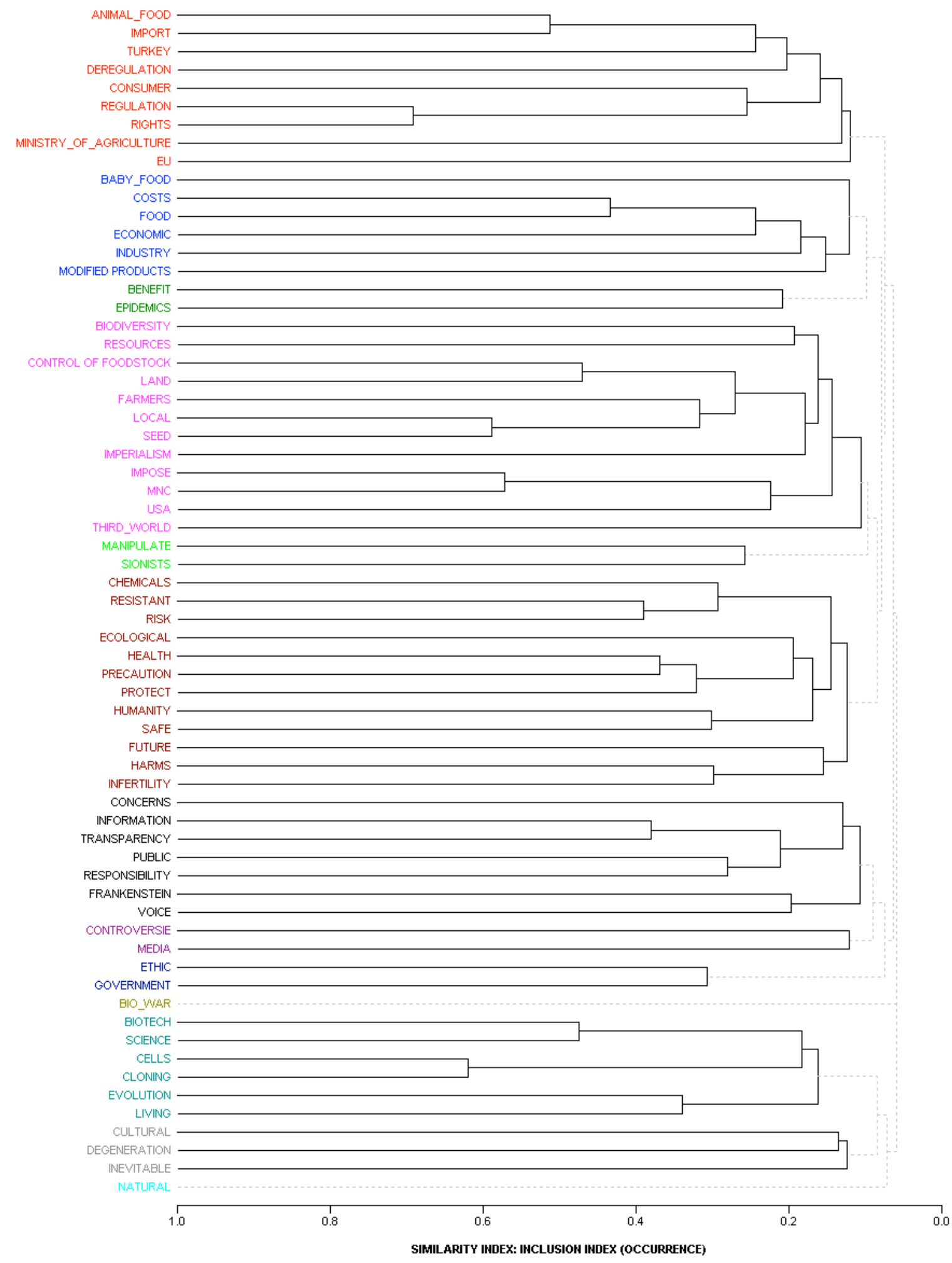

Figure 1 Dendogram of the clustering of keywords

The third stage of the analysis involved the application of labelled thematic categories as coding frames in order to assign codes to paragraphs in the text corpus by a human coder. The full list of thematic categories can be found on the formal concept lattice (Figure 4). 
The final analytical stage involved determining relations between worldviews and themes. This process is particularly important for operationalizing our theoretical framework. According to ANT, technological issues are constructed as a network in which the social, the technical and the symbolic are configured in terms of their interrelationships. In that respect, we grounded our operationalization in the idea that social and discursive relations constitute and reconfigure actors and themes within a signification system. Signification as used here refers both to a semiotic and a political ordering of meaning.

In this respect, Formal Concept Analysis (FCA) is an important visualization tool that can be used for revealing relations between themes and the uttering actors. Depending on the formalisation of the classical theory of concepts (Laurence and Margolis 1999), FCA rests on the definition of a concept as a unit of thought consisting of objects and their attributes. Hence, the network of objects and attributes reveals the definitional structure of a concept and its relations to other concepts. These principles are mathematically formalised as a matrix representing the relations between objects and attributes that are then used to derive a formal concept lattice to visualise the network. For the purposes of this research, different worldviews represent the objects and the coded themes uttered by the columnists in their articles concerning GMO represent the attributes. 


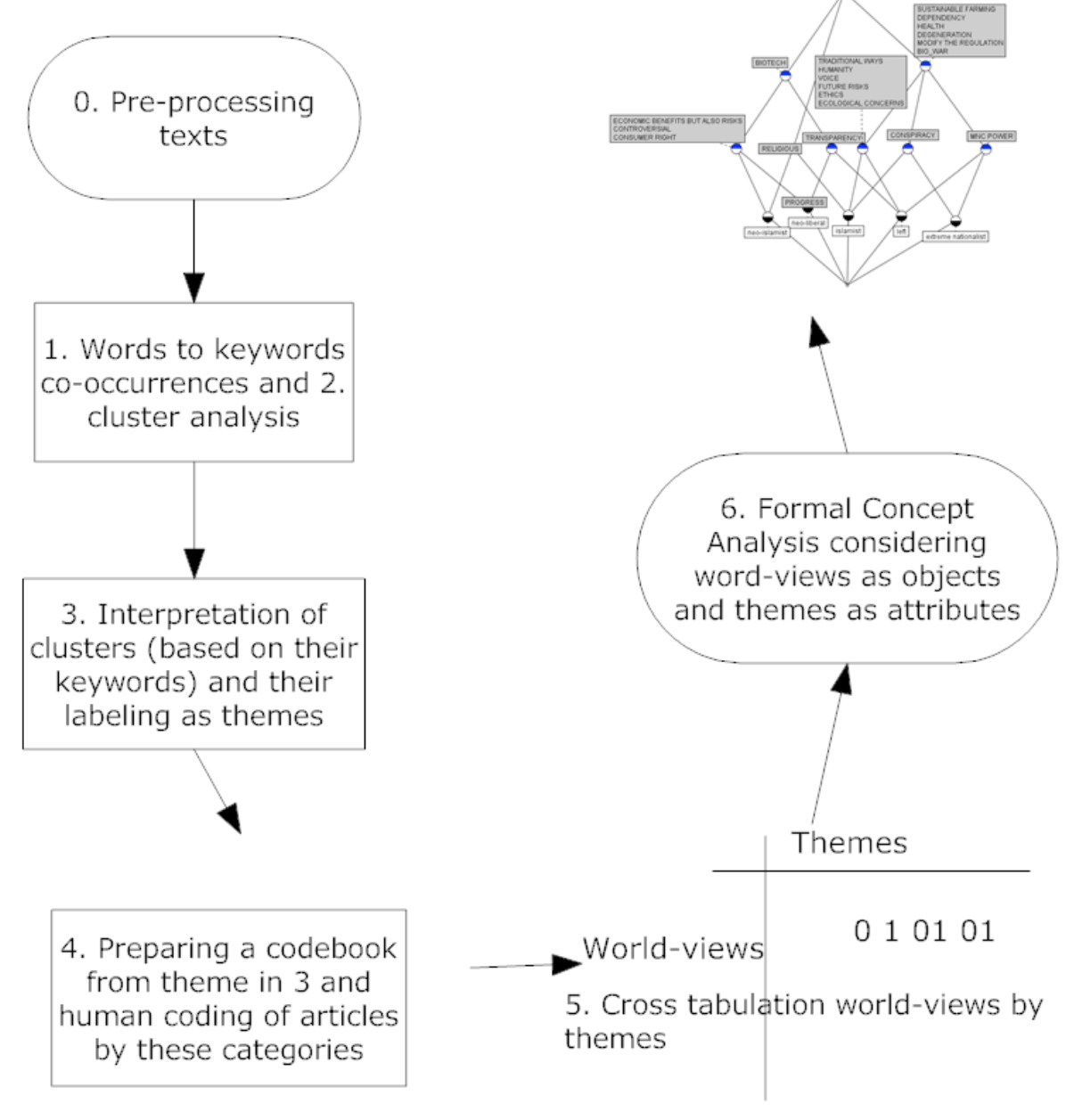

Figure 2 Diagram of methodological steps.

\section{Data Collection}

Context

Genetically modified organisms (GMO) were not a popular topic in Turkey until the regulation addressing the control of food products containing GMO became operative on 26 October 2009. The regulation triggered extensive resistance from agricultural organisations, consumer associations and political parties opposed to it. These controversies found their place in the media by significantly increasing the number of news and articles about GMO (Figure 3). Generally, the debate turned on the defence or criticism of the regulation. Those who defended the regulation argued that Turkey does not yet have a bio-security law that would place GMO-containing products under supervision; hence the regulation was to take care of the issue. Conversely, opponents contested that the regulation does not 
restrict or ban the import or use of GMO products but only introduced some palliative measures that falls short of international standards. However, although the controversy seemed to be a simple and straightforward technical issue, the discussions around it unfolded in a much more complex manner. Behind the manifest content, actors representing different worldviews filtered the risks and benefits of GMO from their own perspectives in order to push their conception of the ideal polity. In that context, this paper focuses on how newspaper columnists embodying different worldviews constitute different representations of GMO-related risks. Newspapers are important media of communication as new developments reach public opinion primarily through them. The press raises new issues and constitutes an arena for the discussion of controversies around these issues. This arena plays an important role in framing everyday conversations and political debate among citizens (Bauer, 2005a). In that respect, the press is particularly central in terms of representing and shaping public perceptions (Bryant \& Zilmann, 1994). Among other mass media, journalists and editors play an important role in the construction of our symbolic environment and hence the dissemination and enculturation of opinions, beliefs and worldviews (Bauer, 2005b).

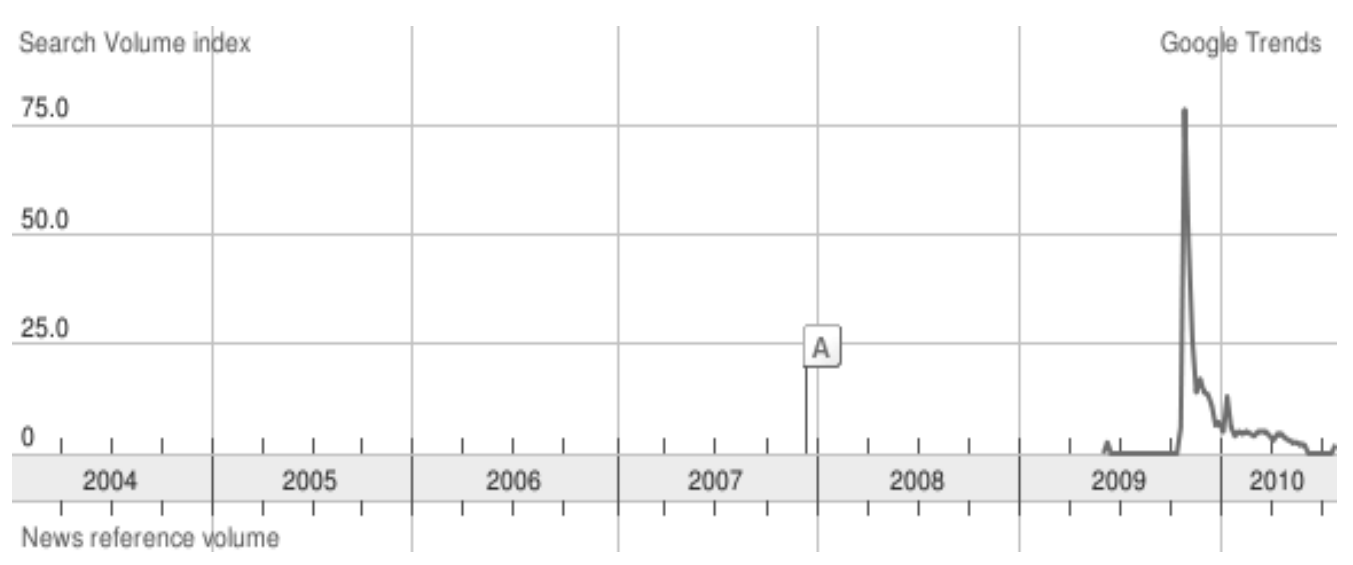

Figure 3 The Google news reference volume and search volume index for GMO in Turkish.

Source: Google Insights

\section{Worldviews}

In 'The Cultural Theory of Risk', Douglas and Wildavsky proposed that "world views" could be classified into four basic categories in a grid/group arrangement. These were termed individualistic, egalitarian, hierarchical, and fatalistic worldviews, which each represent different patterns of risk perceptions shaped by the interaction of an individual with his/her social environment. However, group/grid theory has been criticized on the grounds of being "fatally opaque" and not being supported by sufficient empirical evidence (Boholm 1996). Hence, in our choice of how to tag the 
articles according to the worldviews of the columnists, we did not strictly stick to the group/grid theory, although we agree with the basic premises of the cultural theory of risk.

Historically, four major political and cultural movements: liberalism (right); social democracy (left); Islamism; and extreme-nationalism have constituted the political arena in Turkey (for a detailed analysis of political spectrum in Turkey, see for example: Rubin and Heper 2002; Sayar1 and Esmer 2002). Recently AKP (Justice and Development Party), the governing party since 2002, has joined these movements with a neo-Islamist agenda juxtaposing Islamism to neo-liberalism. Put briefly, AKP conceives political and economic liberalism in a somewhat instrumental manner in their mission to gradually organize the Turkish polity according to Islamist principles. As its name suggests, AKP tries to appeal to the masses by reconciling social justice (which can be maintained by Islamic principles) and growth (which can be maintained by neo-liberal policies). AKP follows a pragmatic discourse oscillating between a compliant discourse aimed at persuading Western and domestic public opinions that they are not following an Islamist agenda, and a combative one, aimed at persuading the Islamic world and their core constituents that they are not bowing to the West and that they are following their own way to the Islamisation of Turkish society (for detailed analyses of how AKP presents its policies as a form of "alternative modernity" see: Keyman and Koyuncu 2005; Buğra and Keyder 2006; Öniş 2007). Within this context, we take columnists as proxies for the positioning of these five political movements. We assume that their articles express the worldview of one of the political movements that constitute the Turkish public sphere.

\section{Corpus construction}

A collection of 45 GMO-related newspaper articles constitute the text corpus. The articles are selected from the web archives of 11 newspapers of different orientations by using the keywords 'GMO', or 'Genetically Modified Organisms' (in Turkish). The time frame of our dataset ranges from articles published just after the regulation came into effect until May 2010. As can be observed from figure 3, almost all of the media references to GMO occurred during that time period. Therefore, the corpus is not a probabilistic sample but an almost exhaustive collection of GMO-related articles.

Among these newspapers, Hürriyet, Milliyet and Vatan are popular newspapers hosting authors from different worldviews. Although Sabah and Star could be included in this category, their editorials usually manifest a more homogenous pro-government position, gathering mostly neo-liberal and neoIslamist columnists. Taraf gathers authors representing the Left, the Neo-liberal and the Neo-Islamist worldviews. Columnists in Yeni Şafak and Zaman represent Neo-Islamist and Islamist views. Columnists in the remaining three newspapers are more homogenous in publishing different worldviews: Milli Gazete represents the Islamist position, Yeni Çăg the Extreme-Nationalist and 
Cumhuriyet Left-wing positions (for a more detailed analysis of press-political party relations in Turkey, see: Çarkoğlu and Yavuz 2010). Because some newspapers include columnists that hold various worldviews, each article was tagged according to the worldview of its author rather than the political position of the newspaper. Two coders (one of the authors and a political scientist) independently assigned columnists to worldviews and the Cohen's Kappa is approximately 79 per cent (Cohen, 1968).

\section{Formal Concept Analysis}

The formal context matrix used in this study is derived using a worldviews-by-themes crosstabulation obtained from the coded texts. In this context, if the difference between observed and expected frequency within a cell was greater than zero, a value of "1" was assigned, indicating that the theme is an attribute of the worldview, and a value of " 0 " was assigned if otherwise. This matrix is then the input for creating a concept lattice representing a joint visualization of worldviews and themes on a two-dimensional space using ConExp 1.3 software (Yevtushenko, 2000). Nodes in the lattice stand for concepts, white filled labels are worldviews, and grey filled labels are themes. If a concept is marked by a certain theme, this means that the upper theme occurred together with all the descending themes. Alternatively, if a concept is labelled by a certain worldview, then the bottom worldview covers all of the themes through ascending paths to the top element of the lattice. We provide a more detailed reading of the lattice in the following sections. 


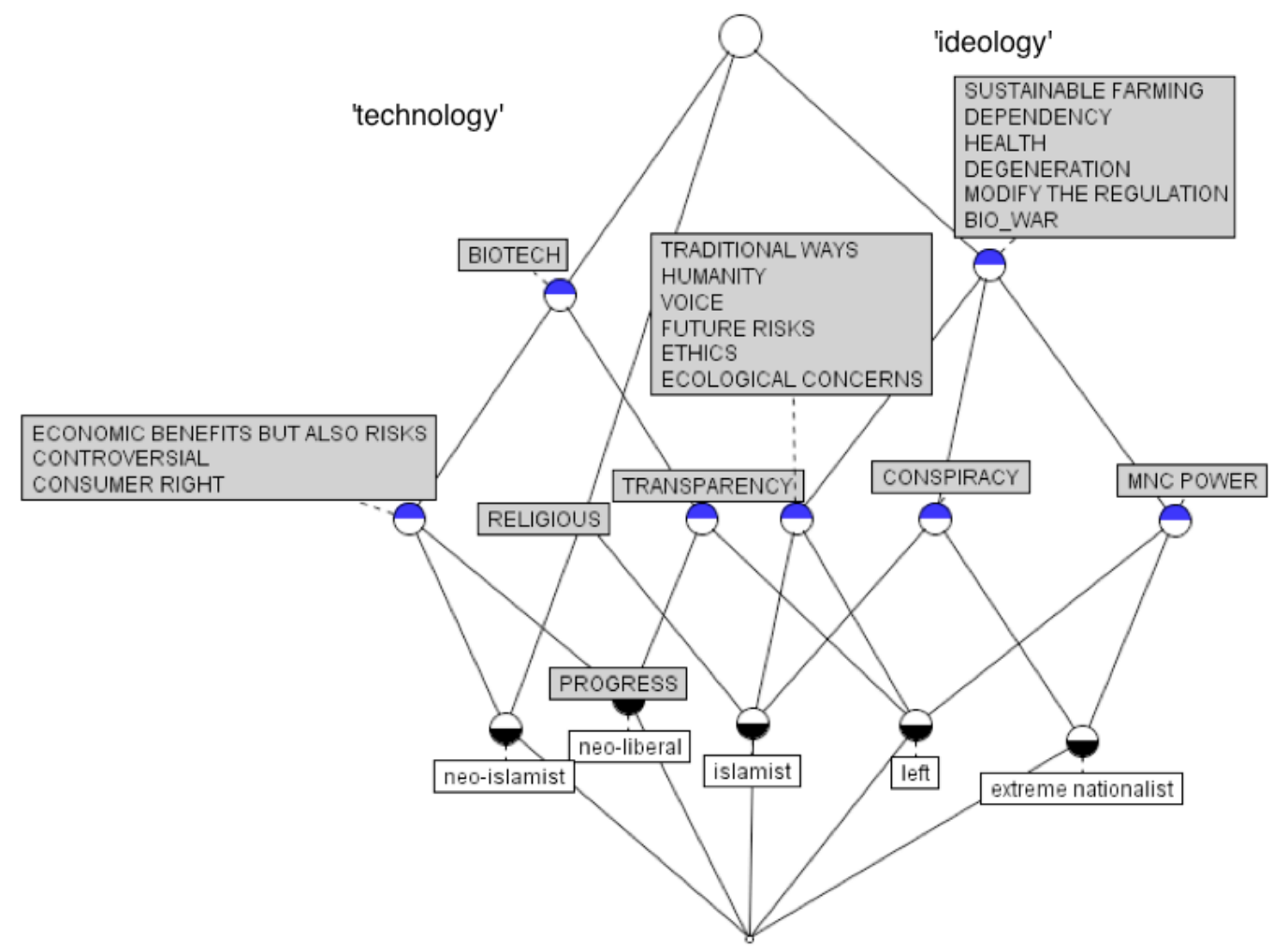

Figure 4 A network representation of the relationships between themes and worldviews. The bottom labels in white stands for the worldviews while the grey boxes for the themes. Upper themes cover those in central or low position.

\section{Interpretive analysis}

Examining the obtained lattice representation (Figure 4), we can observe two separate top level concepts: the one on the right hand side includes a group of themes such as sustainable farming, dependency, health, degeneration, biological war and demand for modification of the current regulation. The Left, Islamists and the extreme nationalists share these themes. The left hand side of the lattice constitutes a single theme: biotechnology shared by the neo-liberals and neo-Islamists. Considering the relations of these concepts to their descending paths, we can clearly distinguish that these concepts represent two different modes of risk perception: The first one represents a critical stance towards GMO by emphasizing its political aspects; the second perceives GMO as a technical issue that should be placed under supervision. A paradigmatic analysis can help us to expand our interpretations further. In semiotic theory, paradigmatic analysis reveals the thematic paradigms underlying the surface level of the text. Paradigmatic relations are the oppositions and contrasts between the themes that belong to the same set (Hodge and Kress, 1988). Accordingly, the use of a 
particular theme rather than another one within a specific context reveals positive or negative connotations of the poles of binary oppositions underlying a discursive construction.

In our example, contrasting the set of themes on the right hand side to the left hand side of figure 4, we can observe that the underlying thematic paradigm points to a 'technology vs. ideology' opposition. Both these themes have positive and negative connotations. In the first theme, the technology theme has a positive connotation, based on the premise that it depends on value-free, objective principles. The ideology theme, on the other hand, has a negative connotation, pointing to its basis in subjective beliefs and assumptions. Therefore, according to these connotations, the intervention of ideological values into science distorts reality in the service of some interest group or other. In the second theme, technology has a negative connotation: a reduction of practical issues to technical problems to be handled only by experts has the potential to depoliticize society by limiting the need for a public, democratic discussion of values. Tackling societal problems as neutral, technical, issues does not liberate science from ideology. Social interests or cultural values always shape the accomplishment of technical principles. Hence, according to this connotation, the discourse of technical neutrality supports the assumptions of the dominant ideology against its challengers, and helps them to resist social critique. This thematic paradigm is archetypical and free from worldviews: each worldview can pragmatically switch to the other side of the pole depending on their power to control a technological movement. For example, neo-Islamists were highly critical about the reduction of politics to technical problems before coming to power but later adopted a highly technical discourse. Moreover, during our analysis some of the columnists of neo-Islamist beliefs still occupied the ideology/value side of this paradigm.

Paradigmatic analysis provides us with insights about archetypal structures. However, this type of structure provides only a coarsely grained picture. For a finer grained interpretation, we need to go further down the paths of the lattice. The first major theme (ideology) path bifurcates into three branches: The first branch shared by the Islamists and the extreme nationalists covers the theme "conspiracy", which perceives GMO as a conspiracy by Jewish Multinational Companies and Israel for world domination. This is comprehensible in the context that many Islamist and extremenationalist groups all over the world explicitly express anti-Semitic views. The second branch perceives GMO as a Pandora's Box and warns of unknown risks such as unanticipated threats, catastrophes concerning future risk, the safety of humanity in general, threats to traditional ways of life, ecological concerns, ethical risks, and calls for a voice for citizens about such threats: The Islamists and the Left share this branch. This shows us that both the Left and the Islamists conceive GMO as a product of capitalist development and are concerned with its future hazards. They both offer their own political solutions. The third branch is concerned that new GMO regulation might be designed to favour the interests of the powerful Multinational Companies (MNC) over national interests: The Left and the extreme nationalists share this branch. 
The second major theme (technology) path bifurcates into two paths: The first branch conceives GMO to be a controversial issue that represents major economic benefits but also some risks. It defends the view that these risks can be allayed by putting GMO under supervision, and by taking precautions to safeguard consumer rights. This view is shared by the Neo-liberals and the Neo-Islamists. The second branch is more concerned about the opacity of the GMO as a technical issue; it calls for more transparent information about the risks and benefits of the GMO. The Neo-liberals and the Left share this view. The latter branch has a sub-branch shared only by the Neo-liberals that conceives GMOs as a progressive development and perceives the controversy as a conflict between the progressives and reactionaries. Our interpretation is that the Left emphasizes more the need for transparency about the risks, while neo-liberals call for transparency about the likely benefits. Finally, a concept that stands alone is about religious concern, which includes such matters as the modifications of products with pork genes, which is forbidden by Islam. This view is obviously shared by the Islamists and the neoIslamists and contains little information value since it is self-evident.

The ascending paths from the bottom (worldviews) to the themes present the political signification of different worldviews towards GMOs. Neo-Islamists and neo-liberals conceive GMOs as a biotechnological issue representing major economic benefits but also some risks. They defend the notion that these risks can be put under supervision by taking some precautions: Neo-Islamists put forward religious concerns; Neo-liberals endorse GMOs as a progressive development misunderstood by the public because of the overstatement of its risks. On the other side, Islamists, extreme nationalists and the Left emphasise the major risks of the GMOs, pointing to the fact that it would harm sustainable farming, create dependency, reduce the numbers of indigenous species, possibly be used as a biological weapon, create health risks. They consequently call for the modification of the regulation. Islamists conceive GMO as a Pandora's Box manipulated by "the Jews" and are concerned about the religious risks. Extreme nationalists also consider GMO as a Jewish conspiracy that would put domestic resources under the control of the MNCs. The Left shares the extreme nationalists' concern about the exploitation of the domestic resources by the MNCs, and the Islamists' Pandora's Box view, but does not put the blame on "the Jews". On the other hand, they consider GMO as a biotechnological issue the risks and benefits of which should be made more transparent to the public.

\section{Conclusion}

Research and policy decisions concerning the risk perception of a new technology have traditionally been focused on whether public opinion towards this technology is forged in an informed or uninformed manner. Such efforts have hence related differences in risk perception to cognitive deficiencies, as a function of the degree of scientific literacy and the ability to draw on reliable sources of information. In line with previous critical studies into the public understanding of science, this paper questions this kind of "public opinion" and "cognitive deficit" model of risk perception. Inspired by SRT, cultural theory of risk and ANT, we challenged the presentation of risk perception 
as a manifestation of a homogenous public opinion. We endorsed and applied the theoretical position that different social actors discursively construct their own risk perceptions as a tool for pushing their political agendas. The debate created by the introduction of a new GMO regulation in Turkey provided us with the opportunity to show how the discourse on risk is situated within the worldviews of the semiotic actors. Our research illustrates how columnists representing the opinions of major political movements in Turkey used risk discourse to project their visions of ideal social and political order onto the public sphere.

Combining quantitative and interpretive methods, our analysis of the newspaper articles demonstrated that besides having different risk perceptions of the GMO, semiotic actors acted as world-making entities. The distribution of themes through worldviews shows that these actors have strategically deployed GMO-related themes to construct their own social and political realities. The structure of the Formal Concept Lattice followed patterns that make sense within the current Turkish political context. Far from being purely a technological issue, the risk perception of GMO is anchored in the worldviews of these actors. For some of them, the perception of GMO as a risk lies in the view that it is linked to the 'usual suspects': GMO is part of a worldwide Jewish conspiracy. For others, besides being a nutritional choice, organic food symbolically objectifies political resistance against economic, political and cultural dependency of the country. In this context, GMO related themes become significant not only in the sense of being a "matter of concern" (Latour 2004), but also as a matter of political signification. Their simultaneous distribution with worldviews reveals a symbolic pattern reflecting both a semiotic and a political ordering of meanings. At first glance, the discursive mapping of the worldviews and themes reflects a 'technology vs. ideology' thematic paradigm. However, a clearer examination depicts the possibilities of different reconfigurations and illustrates the dynamic fluidity of the political space. For example, while the Leftist worldview is proximate to the extreme nationalist discursive position on this cleavage, Leftists are also linked with the neoliberals in the argument that GMO is a biotechnological issue the risks and benefits of which should be made more transparent to the public. Moreover, they are linked with Islamists in the idea that GMO can be a Pandora's Box hiding unknown cultural, ecological, ethical and economic risks and call for more voice. These reconfigurations, compiling different worldviews into discursive coalitions, depict that public sphere as an open, dynamic and fluid semiotic space where meaning is negotiated, articulated and disseminated so as to deconstruct dominant polarizations. The dynamic and multidimensional nature of semiotic space allows for different coalition arrangements framed by different reconfigurations of matters of concern.

Clearly, the dynamic nature of meaning construction in the public sphere is not a new topic and there has been a plethora of research demonstrating the fragmented nature of public opinion from a critical public understanding of science perspective as discussed at the beginning of this paper. However, this 
work adds a number of important of contributions to these efforts. One of the major contributions is to present the topic from a framework that combines SRT with the cultural theory of risk perception and semiotic ANT. Second, it presents a novel mode of combining qualitative and quantitative procedures by basing interpretive analysis in a systematic framework. Our findings suggest the validity of this hybrid methodology as a tool for operationalizing the formation of the public sphere as a fragmented discursive space. Finally, the case of Turkey provides an interesting example since the introduction of the new GMO regulation sparked intense debate, providing rich data for such analysis. It offers a fresh perspective on the study of public understanding of GMO, which has usually been concerned with the European public sphere and has thus come to a point of saturation. In particular, political actors and issues endemic to Turkey may be useful for researchers and policy makers in Europe. The large-scale infiltration of Islamist and Neo-Islamist worldviews into the European political arena through the increasing Muslim population has not yet been sufficiently part of the study of social representations and the public sphere. This study and its findings can provide future researchers with a way of understanding the relationship between such worldviews and their signification strategies. 


\section{References}

Bauer, M. W. (2002). Arenas, platforms and the biotechnology movement. Science Communication, $24,144-161$.

Bauer, M. W. (2005a). Public perceptions and mass media in the biotechnology controversy. International Journal of Public Opinion Research, 17(1), 5-23.

Bauer, M. W. (2005b). Distingushing red and green biotechnology: cultivation effects of the elite press. International Journal of Public Opinion Research, 17(1), 63-89.

Bauer, M. , Allum, N. and Miller, S.(2007) What can we learn from 25 years of PUS survey research? Liberating and expanding the agenda. Public Understanding of Science, 16, 79-95.

Bauer, M. (1994). Popular Science as 'cultural immunisation': The resistance function of social representations. In Guareshi, P.A., Jovchelovitch, S. (eds). Texts on Social Representations. Petropolis-Brazil: Vozes.

Bauer, M. W., \& Gaskell, G. (1999). Towards a paradigm for research on social representations. Journal for the Theory of Social Behaviour, 29, 163-186.

Bauer, M. W., \& Gaskell, G. (2002). Biotechnology: The making of a global controversy. Cambridge: Cambridge University Press

Bauer, M. W., \& Gaskell, G. (2008).Social Representations Theory: A Progressive Research Programme for Social Psychology. Journal for the Theory of Social Behaviour, 38, 4.

Biel, A. \& Dahlstrand, U. (1995). Risk perception and the location of a repository for spent nuclear fuel. Scandinavian Journal of Psychology, 36, 25-36.

Boholm, Å. (1996). Risk perception and social anthropology: critique of Cultural Theory. Ethnos, 68(2), 159-178.

Brun, W. (1994). Risk Perception: Main Issues, Approaches and Findings. In G. Wright \& P. Ayton (Eds.). Subjective Probability, pp. 295-320. Chichester: John Wiley \& Sons Ltd.

Bryant, J. and D. Zillmann, Eds. (1994). Media effects: Advances in theory and research. Hillsdale, NJ: Erlbaum.

Buğra, A. and Ç. Keyder (2006). The Turkish welfare regime in transformation. Journal of European Social Policy, 16(3), 211-228.

Callon, M. (1986). "Some Elements of a Sociology of Translation: Domestication of the Scallops and the Fishermen of St Brieuc Bay." In John Law (ed.), Power, Action and Belief: A New Sociology of Knowledge (London: Routledge \& Kegan Paul).

Callon, M. (January 01, 2007). An Essay on the Growing Contribution of Economic Markets to the Proliferation of the Social. Theory, Culture \& Society, 24, 7-8.

Çarkoğlu, A. and G. Yavuz (2010). Press-party Parallelism in Turkey: An Individual Level Interpretation. Turkish Studies, 11(4), 613-624.

Cohen, J. (1968). Weighed kappa: Nominal scale agreement with provision for scaled disagreement or partial credit. Psychological Bulletin, 70 (4), 213-220.

Colby, B. (1996). Cognitive Anthropology. Encyclopedia of Cultural Anthropology. D. Levinson and M. Ember. New York:, Henry Holt \& Company. 1, 209-214.

Cranach M. von (1992). The multi-level organization of knowledge and action: an integration of complexity. In: Cranach M. von, Doise W., Mugny, G. (eds) Social Representations and the Social Basis of Knowledge: Volume 1. Toronto/Bern: Hogrefe \& Huber Publishers.

DiMaggio, P. (1997). Culture and cognition. Annual Review of Sociology, 23, 263-287.

Douglas, M (1970/1996): Natural Symbols. Explorations in Cosmology, Routledge: New York.

Douglas, M. (1978). Cultural Bias. Occasional Paper no. 35, Royal Anthropological Institute of Great Britain and Ireland.

Douglas, M. (1986). How Institutions Think (1st ed.). Syracuse, N.Y.: Syracuse University Press.

Ellis, R., Wildavsky, A. B., \& Thompson, M. (1990).Cultural theory. Political cultures. Boulder, Colo: Westview Press.

Farr, R.M. (1998). From Collective to Social Representations: Aller et Retour, Culture and Psychology, 4(3), 275-296. 
Fereday, J. and E. Muir-Cochrane (2006). Demonstrating rigor using thematic analysis: A hybrid approach of inductive and deductive coding and theme development. International Journal of Qualitative Methods 5(1), 80-92.

Fischoff, B., Slovic, P., Lichtenstein, S., Read S. \& Combs, B. (2000). How Safe Is Safe Enough? A Psychometric Study of Attitudes Toward Technological Risks and Benefits. In: P. Slovic (Ed.). The Perception of Risk, pp. 80-104. London: Earthscan.

Gaskell, G., Bauer, M. and Durant, J. (1998) The representations of biotechnology: policy,media and public perceptions. In Durant, J., Bauer, M. and Gaskell, G. (eds) Biotechnology in the public sphere: a European source book. London: Science Museum Press.

Guest, G. and E. McLelland (2003). "Distinguishing the Trees from the Forest: Applying Cluster Analysis to Thematic Qualitative Data." Field Methods, 15 (2), 186-201.

Habermas, J. (1989 [1962]). The structural transformation of the public sphere. Cambridge, UK, Polity Press.

Hodge, R. and G. Kress (1988), Social Semiotics. Cambridge: Polity.

Hofstede, G. H. (2001). Culture's consequences: Comparing values, behaviors, institutions, and organizations across nations. Thousand Oaks, Calif: Sage Publications.

Joffe, H. (2003). Risk: from perception to social representation. British Journal of Social Psychology, 42, 55-74.

Keyman, E. F. and B. Koyuncu (2005). Globalization, alternative modernities and the political economy of Turkey. Review of International Political Economy 12(1), 105 -128.

Latour, B. (1987). Science in Action. Cambridge, MA: Harvard UP.

Latour, B. (1992). Pasteur on Lactic Acid Yeast: A Partial Semiotic Analysis. Configurations, 1(1), 129-145

Latour, B. (1999), "'Thou Shalt Not Take the Lord's Name in Vain" - Being a Sort of Sermon on the Hesitations of Religious Speech', Res, 39, 215-23.

Latour, B. (2004). Why Has Critique Run out of Steam? From Matters of Fact to Matters of Concern. Critical Inquiry, 30 (2), 225-248.

Laurence, S. and E. Margolis. (1999). Concepts and cognitive science. Concepts: Core Readings. E. Margolis and S. Laurence. MA, MIT

Law, J. (1992). Notes on the Theory of the Actor-Network: Ordering, Strategy and Heterogeneity. Systems Practice, 5, 379-93.

Law, J. (1999), 'Complexity, Naming and Technology', in John Law and John Hassard (eds) Actor Network and After, Oxford, Sociological Review and Blackwell, 1999, pp 1-14.

Loon, J.V . (2002). Risk and technological culture: Towards a sociology of virulence. International library of sociology. London: Routledge.

Marková, I. (2003). Dialogicality and social representations: The dynamics of mind. Cambridge: Cambridge University Press.

Miller, J. (1983). Scientific Literacy: a Conceptual and empirical review. Daedalus, 112, 29-48.

Moscovici, S. (1973). Foreword. In C. Herzlich (Ed.), Health and illness: A social psychological analysis (pp. ix-xvi). London/New York: Academic Press.

Moscovici, S. (2000). Social Representations: Explorations in Social Psychology. Cambridge: Polity Press.

Moscovici, S. (2001). Why a theory of social representations? In K. Deaux \& G. Philogène (Eds.), Representations of the social: Bridging theoretical traditions (pp. 8-35). Oxford: Blackwell.

Moscovici, S., \& Duveen, G. (2008). Psychoanalysis: Its image and its public. Cambridge, UK: Polity.

Nisbett, R. E., and Ross, L. (1980). Human Inference: Strategies and Shortcomings of Social Judgement. Englewood Cliffs, NJ: Prentice Hall

Öniş, Z. (2007). Globalization and party transformation: Turkey's Justice and Development Party in perspective. Globalizing Democracy: Party Politics in Emerging Democracies. P. Burnell. London, Routledge.

Peledeau, N. (2005). WordStat: Content Analysis Module for SIMSTAT \& QDA Miner User's Guide

Peters, R.G., Covello, V.T. \& McCallum, D.B. (1997). The determinants of trust and credibility in environmental risk communication: an empirical study. Risk Analysis, 17, 43-54.

Rippl, S. (2002). Cultural theory and risk perception: a proposal for a better measurement, Journal of 
Risk Research, 5, 147-165.

Rouquette M.L. et Rateau P. (1998). Introduction à l'étude des représentations sociales, Grenoble: PUG.

Rubin, B. M. and M. Heper (2002). Political parties in Turkey._London, Frank Cass \& Co. Ltd.

Sayar1, S. and Y. R. Esmer, Eds. (2002). Politics, parties, and elections in Turkey.CO: Boulder, Lynne Rienner Publishers.

Slovic P. (2000). The perception of risk. London: Earthscan.

Slovic, P. (1993). Perceived risk, trust, and democracy. Risk Analysis, 13, 675-682.

Slovic, Paul, Melissa L. Finucane, Ellen Peters, and Donald g MacGregor. 2004. "Risk as Analysis and Risk as Feelings: Some Thoughts about Affect, Reason, Risk, and Rationality." Risk Analysis, 24, 311-322.

Suerdem, A. K. (2009). A Semiotic Network Comparison of Technocratic and Populist Discourses in Turkey. Do They Walk Like They Talk? Dissonance in Policy Processes Ed. L. M. Imbeau. NY, Springer.

Suerdem, A. K. (2010). Bridging qualitative and quantitative methods for classifying policy actors into policy discourse communities: thematic analysis and formal concept analysis approaches. Int. J. Data Analysis Techniques and Strategies, 2(3), 199-216.

Verheggen, Th., \& Baerveldt, C. (2001). From shared representations to consensually coordinated actions: Toward an intrinsically social psychology. In J. R. Morss, N. Stepenson, \& H. van Rappard (Eds.), Theoretical Issues in Psychology(pp. 59-67). Boston: Kluwer.

Wagner, W. (2007). Vernacular science knowledge: its role in everyday life communication. Public Understanding of Science, 16, 7-22.

Wildavsky, Aaron B. 1987. Choosing Preferences by Constructing Institutions: A Cultural Theory of Preference Formation. American Political Science Review, 81, 3-21.

Wildavsky, Aaron B., and M. Douglas. 1982. Risk and Culture: An Essay on the Selection of Technological and Environmental Dangers. Berkeley: University of California Press.

Yevtushenko, S. A. (2000). "System of data analysis "Concept Explorer" (In Russian)."Proceedings of the 7th national conference on Artificial Intelligence KII-2000 Russia_127-134. 